The framing of social class distinctions through family food and eating practices

Wills, W.J., Backett-Milburn, K., Roberts, E.M. and Lawton, J.

\title{
Abstract
}

Drawing on two qualitative studies which looked at diet, weight and health from a social class perspective, we use Bourdieu's theory of habitus to help explain the different food and eating practices undertaken by families with young teenagers. Whilst the families displayed considerable reflexivity when making decisions about what to eat on a daily basis, the analysis highlighted that everyday behaviours are still bounded by distinctions of taste, according to social position. The paper includes an examination of the relationships between different forms of capital and whether form or functionality is prioritised within families. We show the importance of temporal frameworks when interpreting classed food and eating practices. 


\section{The framing of social class distinctions through family food and eating practices}

\section{$\underline{\text { Introduction }}$}

Age, cohort, class, gender and ethnicity, along with aspects of space and place are just some of the influences on everyday food and eating practices. In this paper we examine how class-based identities are constructed, displayed and reproduced by families through their everyday food and eating practices. We do this by drawing on two qualitative studies involving parents and young teenagers from working class and middle class backgrounds respectively. Drawing on the work of Bourdieu (Bourdieu $1984 ; 1990)$, we highlight and explore the ways in which the food beliefs and practices of these families can be used to illustrate class debates about social, economic and cultural capital. We also examine the 'purpose' of familial food and eating practices, in terms of their functionality and form and also the different temporal frameworks which appear to influence classed ideologies about food.

\section{Food and eating in families}

Eating is a socially constructed practice. Even when eating alone, the manner in which we shop for, grow, prepare, cook and consume food is imbued with the socio-cultural context or contexts within which people exist or have existed (Mennell et al. 1992; Murcott 1995; Delormier et al. 2009). Social relations within families have received some attention from sociologists in terms of the ways that food and eating reflect and help to (re)construct family ideologies, processes and everyday practices. The foods chosen and the eating practices enacted help to create social order and boundaries within families (Caplan 1997), strengthening bonds (Wright-St Clair et al. 2005) and (re)producing group identities (Valentine 1999). Conflict and tension can also be enacted and expressed by family members - children, for example, refusing to eat what a parent has cooked for them (Wills et al. 2008). Such conflict also highlights how children express their desires for autonomy, through trying to forge some sense of distance from family food norms (Wills et al. 2008). In this sense, children and young people become actively involved in creating a family's identity and are not merely the passive receivers of food or care (Grieshaber 1997). Other work has highlighted women's roles in maintaining and forging social relations within families and how this is illustrated and (re)produced through the 'food work' that women undertake on a daily basis (Charles and Kerr 1988; DeVault 1991). Fathers, whilst tending to be less involved in overall contemporary domestic food provision also play a role in framing familial identities through their contribution to putting food on the (metaphorical) table (Metcalf et al. 2009).

Family food and eating practices do not, however, exist, nor are they (re)produced, in a social vacuum. Rather, they occur as part of a 'network of social relationships' (Delormier et al, 2009: 220) which goes beyond the family. Here we draw on our two qualitative studies which examined the part that social class played in (re)constructing and (re)producing everyday food and eating practices in families with young teenagers. 
We are interested in what Reay (Reay 2005) calls the emotional response to class, the way that class is lived, experienced and 'felt' (Sayer 2005). These studies, by drawing on the perspectives and views of both middle class and working class groups, provide rich insights. This analysis takes us beyond earlier work on food, eating, social class (Charles and Kerr 1988) and relationships within families (DeVault 1991; Grieshaber 1997; Valentine 1999; Wright-St Clair et al. 2005; Metcalf et al. 2009). Our approach has enabled us to use food and eating as a lens onto the broader, class-based contexts of family life, whilst also helping us to understand and explain the very different food and eating practices displayed by the parents and young teenagers in our studies. These data, then, help to illustrate aspects of the habitus and classed distinctions of taste (Bourdieu 1984; 1990).

\section{Class-based distinctions}

Social class can be defined by the structural, economic or cultural components which lead to the unequal or 'unnatural' divisions and dispositions that exist within society (Crompton and Scott 2006). In seeking to explore and understand our middle class and working class families' accounts of their food and eating practices, we have drawn on Bourdieu's concept of habitus. Habitus provides a 'structuring structure' (Bourdieu 1984), an overarching system for classifying practices, the 'generative principle' (Bourdieu, 1984: 173) behind the conditions of all lifestyles. Class becomes enacted and embodied through habitus and therefore it offers a useful lens through which to analyse classed actions relating to food and eating.

For Bourdieu, individuals can no more 'step outside' the boundaries of their classed habitus than an 'outsider' can choose to step in to a completely different world in terms of taking up its associated 'alien' practices and habits. The habitus bounds a set of attitudes, beliefs and behaviours which belong to a particular group of people; it is a series of systems which, developed over time and generations, is the 'milieu' in which individuals live with a collective (un)consciousness. Habitus is often enacted without thought (Adams 2006) and is simply about having a 'feel for the game' (Bourdieu 1990); it is the imprint of social and cultural contexts played out through and by individuals without any conscious thought required by the actors themselves.

Bourdieu has often been criticised for not extensively exploring to what extent individuals reflect on their actions or their social position. It has been argued that if human beings were not reflexive, members of a social group would all act in exactly the same way (Archer 2007) and there would be little evidence of nuanced behaviours or lifestyles. Late modernity is often considered to be synonymous with reflexive identity-making, with social structures like class considered to now play a more minor role than in earlier times (Giddens 1991; Beck 1992). This would mean that 'anything goes' in relation to food consumption. Bourdieu stressed that individuals or groups could alter their practices; their dispositions could 'move on' throughout the lifecourse, although never in a random fashion (Bourdieu 1984). Individuals have at their disposal a 'field of possibles' built on their personal and collective history and the 
cumulative force of previous class dispositions. Bourdieu argued that habitus shapes everything, including new trajectories of behaviour. There is, as it were, a series of boundaries around boundaries. Lash contends that reflexivity operates as a hermeneutic system (Lash 1994); it provides 'rules of thumb', not for individuals but for members of communities. Lash has rejected the notion that post modern societies have become individualised at the expense of socially and culturally constructed norms; he has argued that communities (imagined and real) still rely on shared meanings and practices, even though traditional modes of production have become replaced by modern and postmodern, though nonetheless hegemonic, informationand communication-based structures (Lash 1994).

We might 'see' or interpret reflexive thought or action in our data in a variety of ways. Eating can often be a mundane and therefore tacitly enacted task, though no doubt some eating practices require a more discursive dimension. Individuals might then undergo regular 'inner conversations' (Archer 2007) to reflexively position themselves as being 'like' some people and 'not like' others within and outside their immediate community or social group. This also introduces the notion that there might be 'winners and losers' (Lash 1994) when it comes to having the resources to 'be' reflexive (Adams 2006). Warde (Warde 1994) has argued that those who are more anxious about making socially 'wrong' consumption choices are those who have the least flexibility within a highly valued and embedded system. Hierarchical structures perhaps prevent some families from reflecting on their position or their 'choices', or such structures might limit agency even in the light of a desire to 'trade in' food and eating practices. So, in summary, reflexivity might mediate the habitus, for some people some of the time, but we will use our analysis to argue that the habitus creates the conditions for action within everyday life.

\section{Methodology}

We draw on narrative accounts about food and eating practices from two qualitative studies. In the first, we focused on families from working class backgrounds, as they are at greater risk of being classified as overweight or obese and are thought, generally, to eat a poor diet (Armstrong and Reilly 2003). Families with young teenagers were of interest because young people aged 13-15 years experience a great deal of social, emotional and physiological change during this part of the life course. The ways in which these young teenager's food and eating practices were negotiated or reproduced within the family was therefore felt to be illuminating in terms of exploring classed dispositions and identities.

For the first study, we recruited young people aged 13-15 years in schools situated in predominantly working class areas of eastern Scotland. This was determined primarily by looking at the proportion of children who were eligible for free school meals (FSM). Although FSM status is not a reliable indicator of class or socio-economic status (SES) when used alone, it gave an initial indication of the SES of families living in each school catchment area (Hobbs and Vignobles 2007). A short screening questionnaire was 
administered to consenting teenagers during Personal and Social Education (PSE) classes in schools. The questionnaire collected details on several socio-demographic factors including parental occupation/s, the number of people living in each household, family affluence (Currie 1997) and home postcode. The latter was used to determine whether young people were living in areas classified as being 'disadvantaged' (Gordon and Forrest 1995) and this classification was supplemented by reference to the other questionnaire data, in order to make the final selection of working class families to interview. Half of the 36 teenagers invited for interview were boys and half were girls. Each gave their written consent to participate. Parents of each participating teenager were asked to give their own consent to take part in the study and we conducted individual interviews with 27 mothers, 1 father, 6 grandmothers (the main carers for these participants at the time they were interviewed ${ }^{1}$ ) and 1 grandfather (interviewed with his wife). Teenagers and parents/guardians were asked to talk in depth about their daily food and eating practices and also about their health and weight (Backett-Milburn et al. 2006; Wills et al. 2006).

Some of our findings indicated that our working class families' food and eating practices were underpinned and informed by the circumstances arising from 'being' working class (Backett-Milburn et al. 2006; Wills et al. 2006; 2008). To confirm this we needed to focus, in a second study, on recruiting young people and parents from middle class families ${ }^{2}$. Young teenagers aged 13-15 years were recruited from within the same geographic area as for the earlier study, from schools chosen for their low numbers of students eligible for free school meals. As in the previous work, consenting young people in schools were asked to complete a short screening questionnaire. We chose 36 teenagers to interview whose parent/s' occupations were reported to be in class 1 or 2 of the NS-SEC ((Office of National Statistics 2004). Family affluence was ascertained from positive responses to two items adapted from the Family Affluence Scale (Currie 1997) and postcode sector was assessed using the 2001 Carstairs scores for Scottish postcode sectors (McClone 2004) (with households falling into the least deprived quintile being eligible to participate). To mirror the previous study, half of those selected for interview were girls ${ }^{3}$. Separate interviews were then conducted with 33 mothers and 2 fathers. As far as possible, given the different sample group and different fieldworker in the second study, we replicated the original project in terms of the topics covered.

Attention was paid to ethical considerations throughout both studies (Morrow 1996). Both were cleared by the relevant Education Departments and ethics committees before fieldwork commenced.

Data from the first study were analysed by the research team after repeated readings of the interview transcripts and regular meetings to discuss emerging themes. The data were classified into six very broad thematic codes (consumption and preferences; food at home; food with peers; health; weight; and adolescent context). The same analytical strategy was used for data from the second study and the same six thematic 
codes were used to code these data (three of the four authors worked on both studies). Regular team meetings identified when and how data from the middle class study differed from the previous research and further analysis was then undertaken across the data sets. This included revisiting analyses from the first study in the light of emerging findings from the second study and vice versa, resulting in an iterative process of making sense of the data sets, separately and together. This highlighted new thematic developments which we would not have seen if we had only had one or the other dataset - some practices which could have been ignored as 'ordinary' became 'extraordinary' when seen in relation to data from another social group.

The following analytical description of two illustrative examples draws on field notes written immediately after each interview with, firstly, the teenager and then the parent (the mothers of both case study teenagers were interviewed). The field notes provided context through interviewer observations about where the family lived, details about the family members they met during their visit as well as a summary of the key issues and themes that were raised during each interview. Drawing on the thematic analysis described earlier, excerpts from interviews are also included in the illustrative narrative, where appropriate. All names used are pseudonyms and the data are presented using the dialect of the participants. As we are concerned with how food and eating practices are embedded in social context, we have included data and observations from parent's and young people's accounts of their daily lives which are broader than just food and eating.

Through using illustrative examples, we are able to give a detailed account of two families (one teenager and parent from each study). These families were chosen because our analysis showed that their circumstances and food and eating practices reflected the majority of families in each study (we highlight when this is not the case). This allows us to explore and explain, 'from below', (MacDonald et al. 2005) the everyday lived experiences of two families whose lives were contextualised by membership of different social class groups

\section{Working class example - The Watson family}

Lorraine Watson (aged 13 years) lived with both her parents and had one younger brother. Her father worked 12-hour shifts in a manual job, and then drove a taxi at the weekend. Her mother worked in a local convenience food store, $2 \mathrm{pm}-10 \mathrm{pm}$, four days on, followed by four days off. The family lived in a top floor flat on a large council (social housing) estate in the centre of a medium sized town located in a semi-rural area.

Lorraine helped out at and attended several clubs (e.g. Guides and Rainbows) so she often prepared her own 'tea' after school, before her parents and brother were home. If her father and brother were at home then Lorraine said she cooked the tea. Vegetables were usually only served with the Sunday roast. Lorraine did not consume vegetables if she did not like them (and her mother did not express any expectations 
that she would do so). As well as regular trips to the 'chippy' for takeaway 'fish and chip suppers', Saturday lunch was usually a 'baker's lunch'; Lorraine explained what this was:

'Normally either steak pie or an egg mayonnaise roll and a cream pancake. They're my favourite. I like them and I only get them on a Saturday you know, if we're having a baker's lunch'

Her favourite foods were pizza, bananas and salad. Lorraine said she ate crisps, chocolate and sweeties every day; all of the family had similar eating habits to Lorraine.

At school, Lorraine either had curry sauce and chips for lunch or went to the local petrol station to buy 'microwave chips', crisps and chocolate. She did not take 'free school meals' and we were not sure if she was eligible for them. The only time Lorraine Watson said her food choices depended on money was if she got the breakfast cereal she asked her parents to buy. She was given $£ 2$ per day to buy food during school.

Lorraine does not get an allowance though she does household chores, including taking clothes to the launderette each week so that her parents pay her 'subs' for the various clubs she attends and for her phone card. They will sometimes give her extra money to buy sweeties at the weekend and she sometimes has money left over from buying her lunch at school which she also spends on confectionery.

Interview with Lorraine's mother: Mrs Watson said she or her husband does the food shopping, whoever has the most time when they have run out of food.

She said her husband was currently working $5 \mathrm{am}$ till $4 \mathrm{pm}$ so he cooked when the children were at home (but sometimes he worked 8am-8pm so then he was not there for the evening meal). The Watsons ate a variety of frozen and ready-made food. Ready meals were kept in the freezer 'which come in handy' Mrs Watson said when different family members were coming and going to work, to the launderette or to their choice of activities. When Mrs Watson cooked 'home-made food' it was mainly 'traditional' British ('roast dinners') or Scottish ('mince and tatties') fare. Mr Watson, according to his wife, cooked whatever was easy and could be taken from the freezer, things like fish fingers or chicken nuggets. He would not make 'stews and chicken and that sort of thing' like Mrs Watson did when she cooked. She will also make things like macaroni cheese or spaghetti Bolognese though not usually from scratch.

The Sunday roast was an important family meal and never missed; if Mrs Watson was working a Sunday shift she worked $8 \mathrm{am}-6 \mathrm{pm}$. She prepared the meal (usually a roast followed by a dessert like jam roly poly with custard) before she went to work and heated it up when she returned so the family could all eat together; Mrs Watson's mother often joined them for this meal (friends were never invited to eat with the family). 
Mrs Watson said they were preparing for a holiday at the time they were interviewed (one of the few working class families in the study to mention holidays) and they sometimes bought the children books and CDs:

'Now if it's the likes of new CDs or a video or that or the new Harry Potter book em, which they got the day it was released so they can't complain. They will get it, within reason but I don't go out and...we don't buy on demand in this house'.

Mrs Watson said she had always expected Lorraine (who was asthmatic) and her younger brother (who suffered from epilepsy) to be responsible for their own medication. She also felt that Lorraine was of an age when she could be responsible for the family's laundry and for cooking her own meals when she needed to. Mrs Watson had recently found out that Lorraine had stopped eating in the school dinner hall. She was glad Lorraine had told her she sometimes went to the petrol station; she felt that Lorraine was asserting her independence and was old enough to do what she wanted to and to make her own decisions about what to eat.

\section{Middle class example - The Connell family}

Elspeth Connell (aged 13 years) lived with both her parents and had one younger sister. Her father was an engineer and her mother a solicitor. They lived on the outskirts of a medium sized suburban town in a large, detached house.

After school, Elspeth went to see her horses for two hours, along with her mother and sister (they owned four horses). She went for longer rides at the weekend and she also attended pony club events. Her mother returned from work at 2-3pm; her father usually arrived home between 6-7pm. He used to work in London during the week, but he quit his job and now has a job which meant he was at home more often.

Elspeth said they usually all sat together for their evening meal, which was served in the kitchen. She said they all got to pick one meal they wanted during the week; she and her sister were not allowed to argue over what meals they wanted. Elspeth said that she was not keen on vegetables, but she had to eat them, even if she did not like them.

She said: 'I don't like make a fuss because I know I would get in trouble so I just ...eat'.

Her favourite foods were king prawns, roast pork, fish and lamb. At the weekends she said they might get more 'treat' food like chicken and chips or pizza. During the week she came home from school at lunchtime and she and her sister usually had something like a baguette with chicken tikka masala, heated up in the microwave. She went back to school in time to 'hang out' with her friends. She occasionally went down to the town with her friends for lunch, usually on a Friday, when she would buy a baguette.

Elspeth got an allowance of $£ 5$ a week and she shared a paper round with her sister so they both got $f 5$ from that each week, too. She had her own bank account and was encouraged to save her allowance and money from her paper round. She usually spent her allowance on clothes and make-up; she had recently bought an iPod that she had 
saved for. She was expected to pay for any new riding equipment that she wanted plus downloads for her iPod. She only received money to spend on food on the occasions she wanted to go with her friends to buy a baguette, as usually she ate lunch at home.

Interview with Elspeth's mother: Mrs Connell said her husband did the food shopping; she said that that was the 'rule', that he started to do something to help after she went back to work after having the children. The Connells talked about holidays to the USA (where Elspeth developed a taste for prawns). They hosted (and also attended) regular dinner parties, when Mrs Connell liked to cook three course meals for friends.

Mrs Connell said that she does most of the cooking in the house. She said from Monday to Friday she'll often use a jar of sauce, like 'Loyd Grossman" pasta or curry sauce, but with freshly cooked rice and 'things like that', so it is not totally convenience food. The night before last they had eaten chicken and bacon risotto and the night before that was pork chops with homemade orange sauce and mashed potatoes. The Connells also ate a variety of 'global' dishes like risotto and fajitas. Mrs Connell said her food choices were influenced by a rejection of those of her upbringing, which she described as 'traditional plain Scottish cooking' (hence the focus on more global dishes). 'Family meals' were usually taken together, sitting at a table. Individuals served themselves from central bowls of food and manners were important to Mrs Connell ('I prefer them to sit nicely at the table and eat nicely'). She said very occasionally they get individual meals, but generally she refused to do this. The Connells expected that Elspeth and her sister would eat a variety of food and that they would, usually, eat what was served to them. It was expected that they would eat vegetables, even if they did not like them.

She said that health was an important consideration when choosing what foods to provide. She also said that she thought her husband and Elspeth would be happy to eat a less healthy diet and that Elspeth used to be her 'junk food queen' though 'she's getting better'.

She said that weekends revolved around the girls and their ponies. Mrs Connell said the whole point of having ponies was to avoid having the girls hanging around on street corners. She said it kept them all involved as a family, and they got exercise and fresh air too.

\section{Habitus in the context of food and eating in families}

Distinctions of taste cannot begin to be deciphered unless we look at the 'objects' of consumption which might start to reveal the habitus of our two families. So, we begin by examining the foods routinely eaten by the Watsons and the Connells, making reference to the wider findings from both samples where appropriate. These data are used to highlight the social, cultural and economic capital that the two families seemed to possess.

A striking difference was noted in relation to consumption of dishes like fajitas, risotto and also enchiladas, Thai curries, stir fries and different types of salad (e.g. Caesar 
salad, warm salads); these foods were frequently consumed by the Connells and the other middle class families, but not by the Watsons or their contemporaries. The Connells reported regular holidays abroad and this, alongside more frequent eating out in restaurants in the UK and in other families' homes, perhaps contributed to the cultural distinctions in consumption reported here. Just as middle class families 'buy in' education-focused activities (Vincent and Ball 2007) it seems they can also 'buy into' a culturally richer food heritage by providing a diverse range of foods at home. This has the potential to increase their position of otherness from those who cannot access foreign cultures through food, eating out or travel (Bell and Hollows 2007). The exchange-value of these dishes acts, in effect, to increase cultural capital (Skeggs 2004).

Neo-liberal economics may encourage consumers to buy into the segmented, heavily marketed products aimed at people 'like them' and the Connells were happy to buy cook-in sauces, rather than making a sauce 'from scratch', but they were 'Loyd Grossman' sauces and a not a brand aimed at 'other' people. Mrs Connell's rejection of 'plain' Scottish food suggests that this cuisine had negative connotations for her; that she found such foods, and, importantly, what they stood for, distasteful. Respectability seemed important for Mrs Connell, and as a ubiquitous marker of a classed distinction (Skeggs 1997), choosing not to pass on her Scottish food heritage arguably allowed Mrs Connell to display her social position, to the researcher as well as to her friends and extended family.

Fish was eaten by many families, but whereas the working class families, including the Watsons, mainly consumed 'fish suppers' (that is, battered fish and chips from the 'chip shop') or frozen fish fingers, the Connells, and their contempories, ate fresh fish, prepared at home. Battered fish and chips are a traditional, British meal, the original 'takeaway' before kebab shops and Chinese takeways appeared on every high street in Britain. Fish and chips is a filling, 'no-frills' meal and, as we shall discuss later in the paper, such functionality can be seen as a key factor in defining working class tastes.

The Connells had clear expectations about what and how their children should eat; from their interviews this appeared to involve prioritising variety, not making 'a fuss' and a concern for health. They spoke about teenagers like Elspeth being expected to develop a liking for a wide variety of foods whereas younger children were able to refuse foods (though they were still expected to try them). A liking for 'bland' food was frowned upon, whilst developing a taste for 'spicy' or 'exotic' foods was seen as some sort of 'rite of passage' towards adult tastes (Wills et al. 2009). There was little evidence of this explicit moulding of children's tastes in the Watson family. Whilst some working class parents said they would like their children to eat more vegetables, to try different foods, or to ask before taking some foods or snacks, on the whole young people's tastes and preferences were treated as their own concern (BackettMilburn et al. 2006). Getting older children to make autonomous choices in relation to food and eating seemed to be given a high priority in these families. 
We did not collect data on our families' incomes but we know the parents' occupations. We also visited their homes and asked them about the range of activities they took part in, so we are able to use this information along with the narrative accounts given about everyday food and eating practices to build up a picture of their economically-driven lives. Some of the foods purchased by the Connells, like asparagus, fresh fish and Loyd Grossman sauces were more expensive than those purchased by the Watsons, like tinned sweetcorn and fish fingers. However, the Watsons ate fish and chips, which is also not a 'cheap' way to consume fish, and expressed little desire to eat more 'cosmopolitan' foods like those eaten by the Connells (irrespective of their cost). So does having more money mean easier access to better quality, more nutritious or more highly desirable foods or are choices more directly driven by a social or cultural desire to consume or to not consume particular items? There is a complex fusion and interplay here between these forms of capital, self-identity and the use-value of specific consumption practices (Warde 1994).

\section{Functionality vs. form: What 'purpose' do food and eating practices serve?}

In Distinction (Bourdieu 1984) Bourdieu writes in detail about the functionality of the working class meal compared with the importance of form (over substance) for the middle classes. Whilst some of his empirical writings are inappropriate for exploring contemporary British families (as the data he draws on relate to French life in the 1950-1970s), his description of socially driven food dispositions are relevant when interpreting our data.

The priority for the Watsons was to ensure that all four family members 'got fed'. Dinner was a matter of looking in the freezer (unless Mrs Watson was cooking) and deciding what would be quickest to prepare that would be acceptable to those eating it. 'Outsiders' were never welcomed in to eat - Lorraine's grandmother ate regularly with the family but she could be seen as an 'insider', as 'one of them'.

Having a 'baker's lunch' on a Saturday meant that the family could carry on with their paid work, household chores and other activities. No one had to take responsibility for food preparation, no one had to set the table or get out cutlery and the day could move forward with little interruption, without the need to sit down together to eat. Whilst these accounts might be interpreted as showing a family with a disordered life, with disparate practices forcing them apart, it could equally be contended to suggest a functioning and busy working family, saving time by sometimes eating individualised or pre-prepared, meals.

In the Connell household, there was more evidence of 'restraint and propriety' (Bourdieu, 1984: 196) and of aesthetic ideals being 'played out'. Whilst many parents across our sample expressed a dislike of providing 'everyday' food, Mrs Connell said she enjoyed entertaining and cooking for 'outsiders' and this acted as a way of 'displaying' food and eating practices to their peers. Food and eating, for the Connells and the other middle class families, were also about promoting health; nutritional 
discourses were particularly strong amongst our middle class parents and teenagers (discussed further in the following section). Eating the 'Connell way' was about selfpresentation and also self-preservation - form (aesthetics) over functionality ('getting fed').

Eating in the 'here and now' vs. having an eve to the future: The importance of temporal frameworks

Functionality and form were related to the 'instantaneous' role that food and eating practices played for the Watsons versus the importance that 'the future' played for the Connells.

We have already mentioned that there was a strong nutritional discourse in the middle class families' accounts of food and eating. The Connells said that eating the 'right' foods for 'good health' was important and it also seemed important to them to display this to the researcher. They reported limiting the consumption of foods high in fat, sugar or salt, like pizza, chips and chocolate and focusing on maximising their consumption of 'healthy' foods, like fruit and vegetables. Elspeth, like many of our middle class teenagers, said she was resigned to eating foods she disliked - particularly vegetables, because of their nutritional value and their role in eating healthily. She also said she felt that she sometimes failed at achieving a 'healthy enough' diet. This was one area where our middle class families displayed considerable reflexive and discursive thought. Throughout the interviews a concern about health was connected to growing older and keeping well and helped confirm that parents had different expectations about older children. Many of the middle class parents' accounts suggested that they felt that older children needed to eat well as they headed towards adulthood whereas younger children could 'get away with' poorer eating habits in the short term. For the middle classes, 'fussy' children were children who were not willing to comply with a parent's concerns about a healthy diet - whereas in the working class study 'fussy' children were those who were difficult to cater for (Backett-Milburn et al. 2010). A nutritional discourse was lacking from the Watsons' accounts of their food and eating practices. We have written elsewhere about 'hierarchies of need' in working class families and the reasons that nutrition often falls down this hierarchy. (Backett-Milburn et al. 2006).

Not only was food about discipline and control for the Connells, but their actions meant that food and eating helped them to build cultural capital in a way which would be beneficial for their children's future social capital. Many middle class parents seemed to feed their teenagers in a way which moulded their eating practices for the future (Backett-Milburn et al. 2010); their 'good taste' was being cultivated for future reward. 'Learning' to eat in restaurants for example, or learning to like spicier foods meant they could mould a future adult who would need to call on such dispositions if they were to lead a 'successful' life. Parents expressed frustration if their children were resistant to such moulding, calling them 'lazy' or 'fussy' if they chose an easier food option (e.g. a biscuit) rather than, say, cutting up some fruit to make a fruit salad. 
Expressing a desire that meals should be eaten as a family, around a table, as the majority of our middle class families did (even though many did not achieve this on a regular basis) could be seen as preparation for future social behaviour, if viewed from a classed perspective about family ideologies.

Family ideals amongst the working class were quite different. Allowing young teenagers to develop autonomy was an important consideration, not just in relation to food and eating practices, but also with regard to taking responsibility for their own health (as shown by Mrs Watson's insistence that the children take responsibility for their own medication and illnesses). Autonomy as a teenager was a marker of 'success' in the working class sample. In comparison, middle class families seemed to practice more 'childing' practices (Alanen 2001) with young teenagers in relation to food and eating, in order to control their behaviour and limit their autonomy until a later age. It is perhaps paradoxical that, compared to their working class counterparts, middle class parents in our sample appeared to keep their young teenagers as 'children' for a longer period in this regard, despite the ultimate goal of independence and achievement in adulthood.

\section{Further discussion and conclusion}

By reflexively prioritising nutrition discourses and shaping children's tastes for the benefit of their future lives, the middle class Connell family were able to shape and confirm their self-identity in relation to others (Warde 1994). By drawing on and also reproducing and increasing their social and cultural capital, their practices and beliefs arguably positioned them in a way that maintained their otherness from lower social class groups (Skeggs 1997). The Watsons were not in a position to mimic middle classes practices, because of the boundaries of their economic, social and cultural position, though this family, unlike some others in our study, did not express any desire to change (Sweetman 2003). Can we consider the Watsons to be reflexivity winners, or losers (Lash 1994)? They were not marginalised from their own social group, they were participating as equals and they were succeeding at increasing their social, economic and cultural worth, within their bounded social positions, through the food and eating choices that they made. This is more of a winning position than the one that the Connells were in. The Connells could never reach their goal of eating a perfectly healthy diet; this was particularly so for Elspeth and many of her middle class peers. They spoke about not being 'good enough' because they gave in to the temptation of 'bad' or inappropriate foods. They were intimately aware of the dangers of imperfection because of the socially embedded expectation that they would be civilised and compliant with the dominant discourses of health and nutrition. Reflexivity for the Connells did not leave them feeling like 'winners' within their own social group. This fits with Warde's argument that those who are more concerned about their consumption choices have the most to lose (Warde 1994). 
Our findings also suggest that concepts of multi-dimensional time or temporality (Thomas and Bailey 2009) are an integral aspect of the habitus. Our families drew on time in different ways, with the working class Watson family finding more use for a present-oriented framework whilst the Connells used the a future-oriented approach, which helped to construct and display their middle class identities. The Watsons functioned by reflecting on what needed to be done 'today', with food and eating having to fit into this temporal framework. The Connells prioritised the form of everyday meals, trying to eat together as a family and to cook 'healthy' meals for example, with the conscious or unconscious aim of creating a future for their children. Despite having an 'eye on the clock', the Watsons managed to be flexible with time; routines could bend to meet the changing needs of the family. In contrast, the Connells, being more constrained by a future-oriented framework, tried to ensure that every meal was 'thought through' and met certain criteria. In this respect the working class families we interviewed seemed relatively untroubled by the dynamic rhythms of daily family life whereas the middle class families were constantly seeking to control the flow of time. This sits comfortably with Silva's argument, that routine implies stability (Silva 2002); with the stability of being middle class cushioning individuals from the knocks of daily life.

Families are a key site for the transmission of cultural capital and our findings suggest that middle class families transmit externally-valued beliefs and practices to their children. They want their children to undertake and take pride in food habits which others, outside the family, can see and respect. This contrasts with working class 'internally valued' practices which highlight the importance of eating 'with your kind', at home. This fits with Tomanovic's argument about 'private' versus 'public' classed practices within families (Tomanovic 2004).

These two studies of family food and eating practices shed some new light on how Bourdieu's concept of habitus is constructed, displayed and reproduced. Whilst our families displayed considerable reflexivity in making decisions about what to eat on a daily basis, our analysis helps to illustrate that everyday behaviours seem to be bounded by a class-based 'field of possibles'. Social, cultural and economic capital is, often unconsciously, nurtured and used by working class and middle class families, especially parents. Lash's concept of reflexivity winners and losers was explored and found to be useful in terms of situating our two families within their own social milieu. Concepts of temporality and external versus internal values provided new, interesting insights into how the habitus 'plays out' and why, and how, classed distinctions of taste persist in late modern times.

\section{$\underline{\text { References }}$}

Adams, M. (2006). 'Hybridizing Habitus and Reflexivity: Towards an Understanding of Contemporary Identity?' Sociology 40(3): 511-528. 
Alanen, L. (2001). Childhood as a generational condition: Children's daily lives in a central Finnish town. Conceptualising Child-Adult Relationships.in L. Alanen and B. Mayall (eds). London, Routledge Farmer.

Archer, M. (2007). Making Our Way Through the World. Cambridge, Cambridge University Press.

Armstrong, J. and Reilly, J. J. (2003). 'The prevalence of obesity and undernutrition in Scottish children: growth monitoring within the Child Health Surveillance Programme.' Scottish Medical Journal 48(2): 32-7.

Backett-Milburn, K., Wills, W. J., Gregory, S. and Lawton, J. (2006). 'Making sense of eating, weight and risk in the early teenage years: views and concerns of parents in poorer socio-economic circumstances.' Social Science \& Medicine 63(3): 624-635.

Backett-Milburn, K. C., Wills, W. J., Roberts, M.-L. and Lawton, J. (2010). 'Food, eating and taste: Parents' perspectives on the making of the middle class teenager.' Social Science \& Medicine In Press, Corrected Proof.

Beck, U. (1992). Risk Society: Towards a New Modernity. London, Sage.

Bell, D. and Hollows, J. (2007). 'Mobile Homes.' Space and Culture 10(1): 22-39.

Bourdieu, P. (1984). Distinction: A Social Critique of the Judgement of Taste. London, Routledge and Kegan Paul.

Bourdieu, P. (1990). The Logic of Practice. Cambridge, Polity Press.

Caplan, P. (1997). Food, Health and Identity. London, Routledge.

Charles, N. and Kerr, M. (1988). Women, Food and Families. Manchester, Manchester University Press.

Crompton, R. and Scott, J. (2006). 'Class and family.' The Sociological Review 54(4): 658-677.

Currie, C., Elton, R., Todd, J. \& Platt, S. (1997). 'Indicators of socioeconomic status for adolescents: The WHO health behaviour in school-aged children survey.' Health Education Research 12: 385-397.

Delormier, T., Frohlich, K. and Potvin, L. (2009). 'Food and eating as social practice understanding eating patterns as social phenomena and implications for public heatlh.' Sociology of Health \& IIIness 31(2): 215-228.

DeVault, M. L. (1991). Feeding the Family: The Social Organisation of Caring and Gendered Work. Chicago, Chicago University Press.

Giddens, A. (1991). Modernity and Self-Identity: Self and Society in the Late Modern Age. Cambridge, London.

Gordon, D. and Forrest, R. (1995). People and Places volume II: Social and economic distinctions in England - A 1991 Census Atlas. . Bristol, SAUS Publications and the Statistical Monitoring Unit.

Grieshaber, S. (1997). 'Mealtime rituals: power and resistance in the construction of mealtime rules.' British Journal of Sociology 48(4): 649-666.

Hobbs, G. and Vignobles, A. (2007). Is Free School Meal Status a Valid Proxy for SocioEconomic Status (in Schools Research)? London, Centre for the Economics of Education, London School of Economics.

Lash, S. (1994). Reflexivity and its doubles: structure, aesthetics, community. Reflexive Modernization.in U. Beck, Giddens, A., Lash, S. (eds). Cambridge, Polity Press. 
MacDonald, R., Shildrick, T., Webster, C. and Simpson, D. (2005). 'Growing Up in Poor Neighbourhoods: The Significance of Class and Place in the Extended Transitions of 'Socially Excluded' Young Adults.' Sociology 39(5): 873-891.

McClone, P. (2004). Carstairs Scores for Scottish Postcode Sectors from the 2001 Census. Glasgow, MRC Social and Public Health Sciences Unit.

Mennell, S., Murcott, A. and Van Otterloo, A. (1992). The Sociology of Food: Eating, Diet and Culture. London, Sage.

Metcalf, A., Dryden, C., Johnson, M., Owen, J. and Shipton, G. (2009). Fathers, food and family life. Changing Families Changing Food.in P. Jackson (eds). Basingstoke, Palgrave Macmillan.

Morrow, V. (1996). 'The ethics of social research with children: an overview.' Children and Society 10: 90-105.

Murcott, A. (1995). Raw, cooked and proper meals at home. Food Choice and the Consumer.in D. Marshall (eds). Glasgow, Blackie.

Office of National Statistics (2004). National Statistics Socio-economic Classification User Manual. London, ONS.

Reay, D. (2005). 'Beyond Consciousness?: The Psychic Landscape of Social Class.' Sociology 39(5): 911-928.

Sayer, A. (2005). 'Class, Moral Worth and Recognition.' Sociology 39(5): 947-963.

Silva, E. (2002). Routine matters: Narratives on everyday life in families. Social Conceptions of Time: Structure and Process in Work and Everyday Life.in G. Crow and S. Heath (eds). Hampshire, Palgrave.

Skeggs, B. (1997). Formations of Class and Gender: Becoming Respectable. London, Sage.

Skeggs, B. (2004). 'Exchange, value and affect: Bourdieu and 'the self'.' Sociological Review 52(s2): 75-95.

Sweetman, P. (2003). 'Twenty-first century dis-ease? Habitual reflexivity or the reflexive habitus.' The Sociological Review 51(4): 528-549.

Thomas, M. and Bailey, N. (2009). 'Out of time: work, temporal synchrony and families.' Sociology 43(4): 613-630.

Tomanovic, S. (2004). 'Family habitus as the cultural context for childhood.' Childhood 11(3): 339-360.

Valentine, G. (1999). 'Eating in: home, consumption and identity.' The Sociological Review 47(3): 491-524.

Vincent, C. and Ball, S. J. (2007). 'Making Up' the Middle-Class Child: Families, Activities and Class Dispositions.' Sociology 41(6): 1061-1077.

Warde, A. (1994). 'Consumption, identity-formation and uncertainty.' Sociology 28(4): 877-898.

Wills, W. J., Backett-Milburn, K., Gregory, S. and Lawton, J. (2006). 'Young teenagers' perceptions of their own and others' bodies: A qualitative study of obese, overweight and 'normal' weight young people in Scotland.' Social Science \& Medicine 62(2): 396-406.

Wills, W. J., Backett-Milburn, K., Gregory, S. and Lawton, J. (2008). 'If the food looks dodgy I dinnae eat it': Teenagers' accounts of food and eating practices in socio-economically disadvantaged families.' Sociological Research Online 13(1). 
Wills, W. J., Backett-Milburn, K., Lawton, J. and Roberts, E. M. (2009). Parents' and teenagers' conceptions of diet, weight and health: does class matter? Final report to the ESRC, http://www.esrcsocietytoday.ac.uk/ESRCInfoCentre/Plain English Summaries/ LLH/lifestyles consumption/RES-000-23-1504.aspx.

Wright-St Clair, V., Hocking, C., Bunrayong, W., Vittayakom, S. and Rattakorn, P. (2005). 'Older New Zealand women doing the work of Christmas: a recipe for identity formation.' The Sociological Review 53(2): 332-350.

\footnotetext{
${ }^{1}$ See Wills et al (2008) for a discussion of grandparent-led families

${ }^{2}$ This study was funded by the ESRC. Ref: RES000231504

${ }^{3}$ We also selected teenagers for both studies based on their body mass index (BMI); our analysis of issues around weight is being presented elsewhere; here we focus on everyday food and eating practices where we found that weight status was unimportant.

${ }^{4}$ Loyd Grossman is a television personality who used to present the 'Masterchef' programme in the UK. His range of bottled sauces is marketed as being fresh, using good quality ingredients and inspired by the creator's travels around the world to help the busy cook.
} 